\title{
Technology Enabled Learning Worlds
}

\author{
Ray Adams ${ }^{1}$ and Andrina Granić ${ }^{2}$ \\ ${ }^{1}$ CIRCUA, School of Computing Science, Middlesex University \\ ${ }^{2}$ Faculty of Science, University of Split \\ ${ }^{1}$ United Kingdom, ${ }^{2}$ Croatia
}

\section{Introduction}

We live in a dramatically evolving knowledge society that is founded on the assumption of equal access to relevant skills and technology-dispensed knowledge. If so, then effective inclusion in society requires powerful new learning resources. In this newer social context, organisations may increasingly become learning organisations and employees may increasingly become knowledge workers. At the same time, new levels of accessibility are equally important to motivate the identification and removal of new barriers to inclusion created inadvertently by new technologies. On this basis, our purpose here is to identify and evaluate some of the key issues that are essential to the new types of learning that will be needed by knowledge workers in learning organisations. To do so, we combine expertise in cognitive science and computing science.

First, we present and evaluate three different approaches to human learning supported by technology:

- definition of learning resources; learning resources are defined as information that is stored in a variety of media that supports learning, including materials for example in print, video and software formats,

- definition of (technology-enhanced) learning environments; learning environments, as places arranged to enhance the learning experience, are defined on an interdisciplinary basis comprising three essential components: pedagogical functions, appropriate technologies and social organization of education and

- definition of learning worlds; learning worlds are partially immersive, virtual milieu that deploy smart and adaptive teaching and learning technologies to create novel experiences based on sound pedagogical and psychological principles.

Second, we present and evaluate some key issues that include:

- $\quad$ The changing role of digital libraries to meet the increasing thirst for knowledge.

- How can learning environments be designed and evaluated for accessibility, usability and ambient smartness?

- The design and development of more effective, technology-enhanced learning environments.

- How can ubiquitous learning environments be developed?

- What new assessment methods must be developed to guide the design and development of such systems? 
- How can new technologies such as virtual reality applications and brain computer interfaces be applied to effective human learning?

We show how a simple but innovative synthesis of key disciplines such as computing science and cognitive science, can be deployed in combination with such topics as ergonomics, e-learning, pedagogy, cognitive psychology, interactive system design, neuropsychology etc to create new learning worlds that boost human learning to meet the demands of the $21^{\text {st }}$ century.

\section{A framework for different approaches to human learning supported by technology}

There are at least three different perspectives on human learning, namely learning resources, technology-enhanced learning environments and learning worlds as defined in turn below. As our primary focus is on human learning, our treatment of learning resources, technology-enhanced learning environments and learning worlds etc will also need to have a focus on the human. To do so, we introduce a simple and convenient structure that may help you to see the key issues and what needs to be done with them in the dual context of human learning and e-learning technologies. Only the relevant details will be presented here, but you may wish to follow up any issues of interest or where you need greater clarity, by referring to our reference list.

At a simple but effective level, a human technology system can be captured by a consideration of:

- A user model (a depiction of the requirements, preferences, strengths and weaknesses of the intended users / students)

- A technological model (a description of the key parameters of the technological platforms to be used, permanent, default or current)

- A context-of-use model (a model that captures the relevant aspects of the context or contexts for which the system is intended; namely software such as the operating system, the physical context such as at home or in a street, the psychological context such as working as part of a small or large team and the social / cultural context such as a Western European country or a South American location).

- A task model (a model that captures the nature and features of the task or tasks that the system is intended to support, such as a traveller dealing with emails or a tourist storing and displaying photographs). Here, of course, we are particularly looking at the subset of tasks that are to do with the human acquisition of new knowledge and skills. Also, in this sub-context, the user is more likely to be referred to as a student, learner etc.

To make the above structure a little more concrete, we now present a little more of a typical user model structure. To do so, we have chosen our own user model structure, not because it is the best, but because it is both typical and relatively simple.

As you will see from the diagram (see Fig. 1), Simplex Two is a theory that seeks to capture the key aspects of human information processing by identifying nine components of human cognition and related processes. These nine components have been validated in two recently published studies (Adams, 2007) that show that Simplex Two captures many, if not all, vital, global aspects of human psychology. Readers should consult this flagship paper if they want to consider the justification and natures of each component or module. The theory 
is set out below as a flow diagram in which the human is depicted, in part, as a processor of information. Information enters the system through the senses into a sensory / perceptual system or into a feedback system and then into the Executive Function. This Executive Function orchestrates all conscious activities of the system and the eight other modules. However, each module possesses both memory and the capacity to process and transform any information that it holds. The Executive Function creates the necessary coordination required between the different functions so that a specific task can be carried out.

Each module of Simplex Two captures an important aspect of the human learner's psychology. Each module has been selected for three reasons. First, it is an important overall aspect of human psychology, second it is reflected in the concerns of interactive system designers and third it is identified in the meta-analyses reported by Adams (2007). The nine modules are summarised as follows:

1. Perception / input module. This module deals with the initial registration and evaluation of incoming sensory information and, in conjunction with other modules, initial attempts at sense making.

2. Feedback management. Surprisingly, the human brain seems to have at least two perceptual systems (Milner \& Goodale, 1995), including a second input system that deals with the feedback that arises as a consequence of our own actions (both physical and cognitive). This dichotomy is also found in the interests of system designers and current work on system design (Adams, 2007). This module processes the feedback provided to the learner from the environment and from e-learning resources.

3. Working memory. When we carry out any task, we often have to hold information in our head whilst doing so. For example, we hold a phone number, a password or sets of instructions. This is referred to as working memory (Baddeley and Hitch, 1974; Baddeley, 2000). Timescales vary, but many tasks would be impossible were it not for this function (Ericsson \& Kintsch, 1995). Working memory is an important component of Broadbent's Maltese cross theory (Broadbent, 1984), a theory from which Simplex has developed. This module of Simplex keeps and processes the information that we need to hold in mind whilst carrying out our tasks.

4. Emotions and drives. When we are dealing with incoming information, it is often of some significance to us, rather than being neutral. It may be interesting, threatening, stressful, frustrating, relevant etc. The human mind is quick to determine if something in our environment is a threat or an attraction and to respond accordingly. This module deals with the emotional and motivational responses to events, imbuing them with significance and meaning. Even with e-learning, the student's emotions and motivations become engaged and exert a significant influence on learning and performance. For computer learning systems, the designer must take significant account of the intended learners' emotional and motivational responses. Do they enjoy using the system or is it irritating or frustrating? Do they find the system a source of motivation or discouragement?

5. Output. This module stores and selects the correct responses that a student needs to make in a given context to a given stimulus. To do so, it must set up and hold the required response in memory and to build up a long-term repertoire of possible responses associated with specific context and stimuli.

6. Output sequences. In many cases, the learner must construct a complex sequence of responses as an important aspect of new skill acquisition. For example, we often learn a 
sequence of keystrokes on a computer that are required to carry out a task, such as sending out an email. The complex sequence of actions seems to "fire off" without reference to specific contexts or stimuli for specific actions. Both researchers and designers make the distinction between responses and complex response sequences.

7. Long term memory. This module provides the long term storage and processing of the knowledge that we require to carry out everyday activities such as studying and developing skills. It is the major source of declarative knowledge i.e. knowledge that we can declare. It also provides that information to support the tasks that need it. For example, consider when a symbol on a computer screen reminds us of something we saw once before or when we need to remember what a specific symbol means. Some tasks require only a little of our knowledge (for example, simple same different judgements) whilst other tasks depend upon much greater quantities of learned information, for example language translation.

8. Mental models. This module provides the capacity to create and retain the mental models that are required to conduct specific tasks, such as navigating around the University Library or around a supermarket, solving logical problems (Some As are Bs, some Bs are Cs; are some As also Cs?) or counting the windows in your home.

9. Executive functions. The Executive Module transfers information between the different modules, transforms information, retains a record of current progress and records the transactions / structures that are required to carry out a task or set of tasks. It also learns to create more efficient transactions / structures with feedback. The Executive Function is far from being a homunculus (a fictional person in your head that tells you what to do) but is an important component of human cognition. It is often associated with the frontal lobes of the human brain such that injuries to these areas can result in disastrous failures of executive functions.

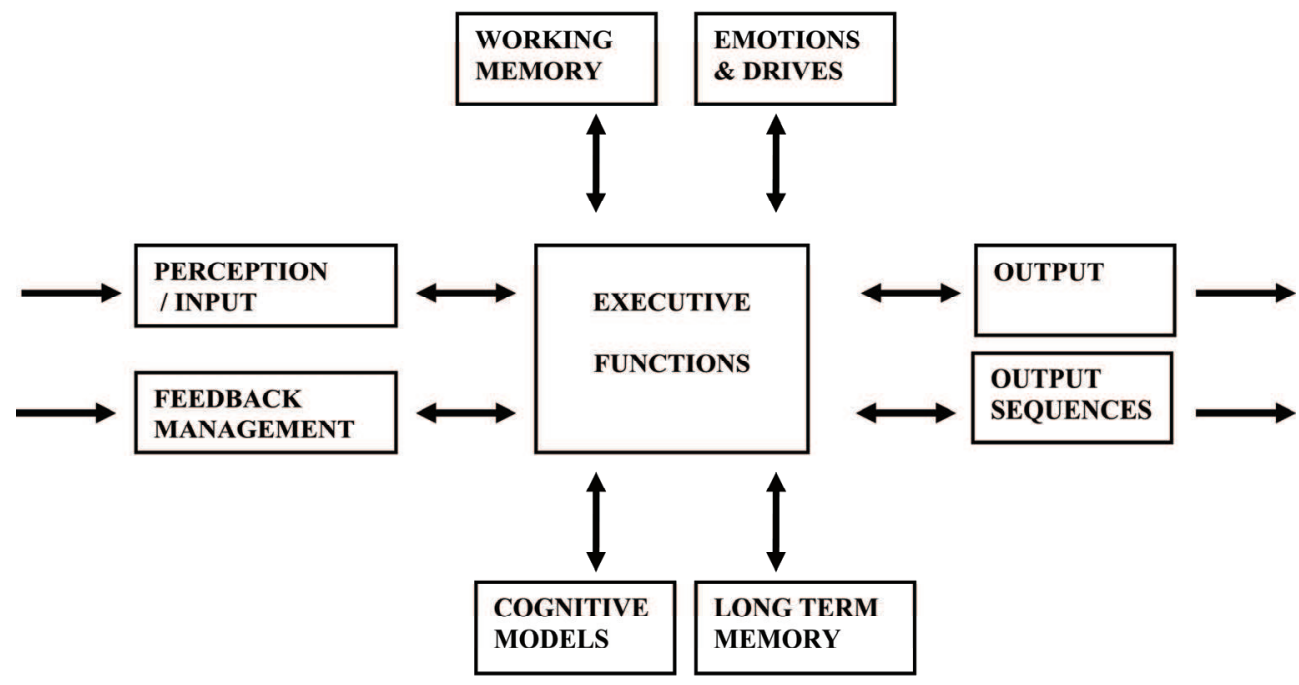

Figure 1. Simplex two 


\section{Learning resources for e-learning students}

Learning resources are defined as information that is stored in a variety of media that supports learning, including materials for example in print, video and software formats. Considering the nine-point approach to Simplex Two, resources can be classified accordingly, relating to each of the nine components. The educationalist should consider each of the following nine fields when designing learning resources for their intended students.

1. Input resources refer to the different human senses with which information is received and understood. For example, information may be presented in different ways (e.g. audio or visual) or through multimedia (e.g. audio, visual and video). Each type of input has different types of features that may be more or less helpful for different tasks. For example, sound may be dramatic and impressive but visual materials are more persistent.

2. Feedback is considered to be essential to successful learning by most experts (e.g. Annett, 1994; Juwah et al, 2004). But it can be delivered in many different ways and through many different modalities (sight, hearing etc). Juwah et al suggest that principles of effective feedback can be identified. They tentatively suggest the following seven features of good feedback. It will facilitate self-assessment and reflection, stimulate teacher and peer dialogue, clarify the nature of good performance, (goals, criteria, standards expected), give opportunities to close the gap between actual and required performance, deliver high quality information to support positive thinking and give teachers the information that they can use to enhance teaching.

3. Working memory is now recognised as an important contributory factor to intelligent human performance and learning (for example Engle, Tuholski, Laughlin and Conway, 1999; Baddeley, 2000; Oberauer, Schulze, Wilhelm and Su" $\beta, 2005)$. If so, the educationalist should be careful to allow the intended students to work within their working memory capacity most, if not all, the time. Learning resources should be presented in bite-sized chunks and be relatively digestible.

4. The emotions and drives of the students are important for learning success. O'Regan (2003) has concluded that emotions are central and essential to e-learning. Sankaran (2001) stressed the importance of motivation in e-learning. Clearly, learning resources must be chosen carefully to aim for a positive-emotion student experience and be suitably motivating, especially when using controversial or sensitive materials.

5. The response requirements of the developed learning resources should enable students to make appropriate responses that are neither too difficult nor arbitrary.

6. The learning resources should support the students in their attempts to develop complex and skilled response sequences.

7. The learning resources should not make unrealistic demands on the prerequisite knowledge that students must possess before they can participate in the proposed. They should not overload long-term memory.

8. The learning resources should be organised and presented to as to enable students to create suitably adequate mental models with which to structure newly acquired knowledge.

9. The students need to be supported so that they can deploy and develop their executive skills to develop overall learning strategies. 


\section{Technology-enhanced learning environments}

Learning environments can be characterized as places arranged to enhance the learning experience. They are defined on an interdisciplinary basis based on three essential components: pedagogical functions, appropriate technologies and the social organization of education.

Widdowson (posted 21 $1^{\text {st }}$ May, 2008) asks "We can only create effective learning environments once we are clear about learning itself. What learning should young people be engaged in and what should learning be like for our 21st century learners, both today and in the future?" The author goes on to suggest some critical questions. They include (our wording) the following. What learning spaces are needed to create better opportunities for active, practical, collaborative, individual and constructive learning that engages the students? How can we design learning spaces to enable learners to develop and progress? How can measure learning environment effectiveness? Do our learning environments challenge and inspire young people? How do our learning environments support flexibility and student diversity?

We suggest that systematic and substantial answer to these questions and other related questions depends, in part, upon the development of a framework such as Simplex Two, or something better. As Widdowson (2008) concludes, the design of a learning space must be based upon an understanding of learning itself. We would also add that it should also be based on an appreciation of the diverse skills, requirements and preferences of the intended students (Adams, 2007; Adams and Granić, 2007). Clearly, learning environments must be fit for purpose (Day, 1995). One way to ensure fitness for purpose of e-learning materials is the creation and maintenance of different versions that are suitable for the different student populations (i.e. versioning: Brooks, Cooke, and Vassileva; 2003). Second, they should also inspire a sense of wonder about learning itself. To quote Albert Einstein "The most beautiful thing we can experience is the mysterious. It is the source of all true art and science. He to whom this emotion is a stranger, who can no longer pause to WONDER and stand rapt in awe, is as good as dead: his eyes are closed"

(http://www.quotationspage.com/quote/1388.html; accessed August 08).

For example, McGinnis, Bustard, Black and Charles (2008) have argued "e-learning should be enjoyed in the same way (insert: as computer games) and can be enhanced by incorporating games techniques in e-learning system design and delivery." However, Burg and Cleland (2001) have cautioned that poorly implemented computer based learning can also destroy any sense of wonder in learning. Third, learning environments must also be accessible. For example, Williams and Conlan (2007) would counteract cognitive accessibility problems by providing a means whereby users can visualize the complex space in which they are learning. In fact, accessibility problems can be found at any of the nine components of human information processing presented by Simplex Two (see above). A complementary approach is offered by Adams, Granić and Keates (2008), as shown in Table 1 below. They proposed five levels of accessibility that can be applied to an e-learning system and parallel them with the Internet layered model. They are hardware access (problems caused by lack of access to the necessary technology), connectivity access (problems with access to systems and resources), interface access (design of the interface creates accessibility difficulties), cognitive access (problems of navigation and accessing the contents of an application or website) and goal / social access (where a system allows you to access your goals). The e-learning system developer should find it a simple process to 
monitor these five aspects of the accessibility of their system. These five aspects can be applied to both the specific requirements of their intended users and to the challenges set by the design of the e-learning system itself.

\begin{tabular}{|l|l|l|}
\hline Comparing: & Accessibility types & Internet layered model \\
\hline 1 & hardware access & physical \\
\hline 2 & connectivity access & data link \\
\hline 3 & interface access & network \\
\hline 4 & cognitive access & transport \\
\hline 5 & goal / social access & application \\
\hline
\end{tabular}

Table 1. Accessibility and the Internet layered model

\section{Learning worlds}

Learning worlds (or environments) are partially immersive, virtual milieu that deploy smart and adaptive teaching and learning technologies to create holistic and novel experiences based on sound pedagogical and psychological principles. The learning world or environment provides the learner with a consistent, familiar and over-arching context in which the user can access a range of different learning experiences and systems. They can also be personalised to match the requirements, strengths and weaknesses of an individual learner, creating higher levels of accessibility whilst still supporting collaborative working. For example, van Harmelen (2006) argues that learning environments can support different pedagogic methods, be collaborative or personal, easily extended or not, capable of supporting customisation or not and controlled by teachers or students or some balance of both. Learning worlds can vary significantly in a number of dimensions. First, learning worlds vary significantly in size. For example, Warburton and Pérez-García (2008) present the concept of the massive multi-user virtual environment (MUVE), whilst Blanc-Brude, Laborde and Bétrancourt (2003) present a learning micro-world. Second, learning worlds can be outdoors and mobile. For example, Chang, Shih and Chang (2006) present outdoor mobile learning, whilst most applications are located within traditional physical settings. Learning worlds can focus on different aspects of learning. Whilst, some learning worlds focus on cognitive skills (Jackson and Fagan, 2000) others focus on social factors. Skog, Hedestig and Kaptelinin (2001) report the Active Worlds system that is designed to support social interactions in 3D virtual learning spaces for distance education. The aim is to build on tacit aspects of social knowledge that are seen as critical for effective learning. A long list of these dimensions could be constructed, but the main point to be drawn is that learning worlds have the power to serve a wide variety of different learning objectives. The two caveats we would add are as follows. (a) The sheer power of the learning world concept means that it needs very careful handling. Technology for its own sake can detract from the learning experience unless learning world designs are learner centred. (b) Learning world designs should be sensitive to the accessibility requirement of the intended users. 


\section{The changing role of digital libraries to meet the increasing thirst for knowledge}

It is clear that digital libraries contribute substantially to the provision of structured, declarative knowledge to online communities of students and scholars, who need to have substantial, accessible cognitive resources at their fingertips. Such libraries represent a major investment of both applied computing science and pedagogic expertise. They proffer potentially very valuable support for learning through the building of smart learning environments. At the moment, sad to say, digital libraries are often set behind monolithic interfaces that can offer an overwhelming richness of data. But that should not blind us as to their potential to provide smart, accessible, cognitive support for human learning in the context of the inclusive knowledge society.

There is no doubt that Digital Libraries can be an exciting and impressive way for students to glean new knowledge without straying too far from the study. They certainly offer considerable volumes of declarative knowledge to students working within the context of the modern Information Society. At the same time, some of our students find Digital Libraries to be difficult to use and the contents of Digital Libraries difficult to access. There is a considerable volume of work if we are to go beyond the simply impressive nature of the size and contents of Digital Libaries to develop the extent to which current and future digital libraries, can be made sufficiently usable, accessible and smart to support an inclusive information society and the aspiration of universal access (for example; Adams and Granić, 2007). These authors used a set of converging methods (separate measures of usability, accesibility and system smartness) to evaluate a random sample of digital libraries through their websites. They concluded that, whilst Digital Libraries are both substantial and functional repositories for knowledge, they can be improved significantly, particularly in their accessibility and smartness. They presented substantial statistical significance levels in their data. A new measure of system smartness is introduced and found to provide a useful metric for present purposes, though it is clear that further work will be needed.

\section{How can learning environments be designed and evaluated for accessibility, usability and ambient smartness?}

Many digital libraries are impressive in principle but often difficult to use in practice. If so, what comes after the present generation of digital libraries? One more future-proof concept is the notion of the ubiquitous knowledge environment or post-digital library. It is defined by its aims. They include the achievement of suitable levels of accessibility, usability and smartness for their structures, contents and their user interfaces. A second aim is to make the post-digital library available on a more ubiquitous and mobile basis. The first step towards such developments has been the evaluation of current digital libraries to identify their potential to support inclusive, smart ubiquitous knowledge environments (Adams and Granić, 2007). Clearly, the second step is begin to develop new designs for these ubiquitous knowledge environments, in the light of the specific design issues raised by current work. Can digital libraries become smarter and more accessible, in so doing creating ubiquitous knowledge environments? The concept of the ubiquitous knowledge environment seeks to capture the potential for convergence between current and future technologies, moving towards towards ambient intelligence and ubiquitous computing. Such knowledge environments move beyond the desktop or laptop to form part of our physical 
environments. Thus we should consider the creation of smart settings, with ubiquitous knowledge environments as a vital component. Access to the knowledge encapsulated would be processed through smarter everyday artifacts that deploy sensor data based responses in order to provide the users with relevant, user-model specific, situation-aware and context-of-use-aware knowledge at the point of use.

\section{The design and development of more effective, technology-enhanced learning environments}

Clearly, there is a long way to go in the development of better technology-enhanced learning environments. On the one hand, there is potential applicable power of new technologies that deliver learning materials and support student / system interactions in ways that are impressive, at least to the system designers and educators, if not always to all of the intended students. On the other hand, there is a growing awareness of the importance of insights into (a) the psychology of human learning coupled as well as into (b) the diversity of human learning requirements and related user modelling to capture that diversity. The danger is that we depend upon the impact of new technologies, 3D effects, virtual worlds, augmented realities, ambient intelligence in support of trivial applications etc. On the contrary, we must attain a basic level of understanding of the diversity of human learning and how to create user-sensitive methods with which to learning environments.

As discussed above, learning environments must, inter alia, be fit for purpose, usable and accessible, also responding to learner interactions in smarter ways. Drawing upon emerging technologies that are subjugated to learning objectives, the development of ubiquitous knowledge environments must also draw upon advanced design and development methodologies. Such advanced methodologies should pay sufficient attention to the evaluation of system relevance, fitness for purpoe, usability and acessibility based upon robust measurement methods.

\section{How can ubiquitous learning environments be developed?}

If higher standards of user satisfaction, usability, accessibility and system smartness can be achieved, then it would be possible to create convergence between technologies such as digital libraries, artificial intelligence (in the weaker sense of simulating human behaviour), ambient intelligence and ubiquitous computing. The substantive contents of such knowledge environments could be unleashed into the external, physical world rather than staying on the desktop or laptop. If so, the present methods of questionnaire based evaluation would focus not only on significant components of the smart environment like the smart digital library, but more so on an evaluation of the overall, smart environments themselves. These methods, or their successors, could be used to design and evaluate better ubiquitous knowledge environments. Access to the knowledge encapsulated would be accessed and processed through smarter everyday artefacts that deploy sensor data based responses in order to provide the users with relevant, user-model specific, situation-aware and context-of-use-aware knowledge at the point of use. 


\section{What new assessment methods must be developed to guide the design and development of such systems?}

Clearly, Digital Libraries provide a useful and invaluable source of knowledge on a wide range of subjects, for a significant number of scholars and students. There can be few working scholars who do not make use of them. Digital Libraries are, at the moment, set behind monolithic interfaces that are typically accessed from the desktop or laptop environments in working or academic buildings. Surprisingly, however, the sample of libraries evaluated here clearly needed improvements in both accessibility and smartness. (These questionnaires are available from the authors). Clearly, if digital libraries are to form the basis for the realization of ubiquitous knowledge environments, they will become smarter and more accessible. We strongly recommend that Digital Library developers and redevelopers should evaluate their systems for user satisfaction, usability, accessibility and system smartness. One approach would be to use expert judgements but an equally important approach is to involve a sample of intended users, building useful user models in the process.

\section{How can new technologies such as virtual reality applications and brain computer interfaces be applied to effective human learning?}

Exciting new technologies, such as virtual reality applications and brain computer interfaces offer new potentialities for e-learning for the twenty first century. Virtual reality applications (VRAs) allow us to create virtual learning worlds in which dangerous, risky, expensive or unexplored skills can be explored and acquired. However, it is clear that the design of such virtual worlds is not easy. Whilst design heuristics can guide their design, it turns out that VRA effectiveness depends on different design points than, say, a website. This, in turn, means that developers should use VRA specific design heuristics.

In the above discussions and analyses, we have shown how a simple but innovative synthesis of key disciplines such as computing science and cognitive science, can be deployed in combination with such topics as ergonomics, e-learning, pedagogy, cognitive psychology, interactive system design, neuropsychology etc to create new learning worlds that will augment and boost human learning to meet the demands of the $21^{\text {st }}$ century.

\section{Conclusions and Recommendations}

There are a number of important recommendations to both the practitioner and the researcher in the advancing world of e-learning environments. First, perhaps most importantly, advances in technology per se should not be confused with advances in human learning capabilities enhanced by technology. Whilst it is clear that technological innovations offer the potential of exciting new developments in e-learning in functionality, usability and accessibility, it is also now clear that new technologies can create new problems for e-learning system design. For new technologies, new design heuristics may be needed, since the critical success factors of design change, not only with different groups of intended students but also with different types of technologies. Second, this first point leads to the second point, namely the importance of user-sensitive design, where both the student and the teacher should be viewed as users of the system. The system design should not only support the requirements of each type of user, but also support true collaboration 
between them. The importance of prototyping, user and expert evaluations and iterative design methods should all be used to support user sensitive design. Third, powerful, effective but simple methods of evaluation of e-learning systems should be used, including functionality, fitness for purpose, usability, accessibility and system smartness. We have used a series of questionnaires that we can give you to support expert and user judgement. Clearly, there is potentially a great diversity of different types of e-learning environments, with an equally diverse range of learning objectives to be achieved. These diversities should not be seen, in themselves as problems, but rather as opportunities to make the current and growing diversity of the teachers, students, researchers and practitioners who wish to use the best and mot relevant -learning system available to them

\section{References}

Adams, R. (2007). Decision and Stress: Cognition and e-Accessibility in the Information Workplace. Universal Access in the Information Society. 5, 363-379.

Adams, R. and Granić, A. (2007). Creating Smart and Accessible Ubiquitous Knowledge Environments. Lecture Notes in Computer Science. 4555, 13-22. Springer Berlin / Heidelberg

Adams, R., Granić, A. and Keates, L. S. (2008). Are ambient intelligent applications more universally accessible? In Universal Access to Novel Interaction Environments: Challenges and Opportunities CHAIR: C. Stephanidis. In AHFE International 2008.

Annett, J. (1994). The learning of motor skills: sports science and ergonomics perspectives. Ergonomics, 37, 5-16.

Baddeley, A.D., Hitch, G.J. (1974). Working Memory, In G.A. Bower (Ed.), The psychology of learning and motivation: advances in research and theory (Vol. 8, pp. 47-89), New York: Academic Press.

Baddeley, A.D. (2000). The episodic buffer: a new component of working memory? Trends in Cognitive Sciences, 4, 417-423.

Blanc-Brude, T., Laborde, C. and Bétrancourt, M. (2003). Usability of speech based and multimodal interaction in a learning micro-world. IHM 2003: Proceedings of the 15th French-speaking conference on human-computer interaction on 15eme Conference Francophone sur l'Interaction Homme-Machine

Broadbent, D.E. (1984). The Maltese cross: A new simplistic model for memory. The Behavioral and Brain Sciences. 7 (1): 55-68.

Brooks, C., Cooke, J. and Vassileva, J. (2003). Versioning of Learning Objects. Proceedings of the 3rd IEEE International Conference on Advanced Learning Technologies 296- 297.

Burg, J. and Cleland, B. (2001). Computer-Enhanced or Computer-Enchanted? The Magic and Mischief of Learning With Computers. ED-MEDIA 2001 World Conference on Educational Multimedia.

Chang, C., Shih, K. \& Chang, H. (2006). Some Studies on Technology Support for Outdoor Mobile Learning. In E. Pearson \& P. Bohman (Eds.), Proceedings of World Conference on Educational Multimedia, Hypermedia and Telecommunications 2006 (pp. 1170-1177). Chesapeake, VA: AACE.

Day, C. W. (1995). Qualitative Research, Professional Development and the Role of Teacher Educators: Fitness for Purpose. British Educational Research Journal, 21,. 357-369. 
Engle RW, Tuholski SW, Laughlin JE, Conway AR. (1999). Working memory, short-term memory, and general fluid intelligence: a latent-variable approach. J Exp Psychol. Gen.,128, 309-31

Ericsson, K. A., \& Kintsch, W. (1995). Long-term working memory. Psychological Review, 102, 211-245.

Jackson, R. L. and Fagan, E. (2000) Collaboration and learning within immersive virtual reality. CVE '00: Proceedings of the third international conference on Collaborative virtual environments. New York, NY: ACM.

Juwah, C., Macfarlane-Dick, D., Matthew, B., Nicol, D., Ross, D. and Smith, B. (2004). Enhancing student learning through effective formative feedback. The Higher Education Academy Generic Centre - June 2004. (copy available from the present authors).

McGinnis, T., Bustard, D.W., Black, M. and Charles, D. (2008). Enhancing E-Learning Engagement using Design Patterns from Computer Games. First International Conference on Advances in Computer-Human Interaction IEEE ACHI 2008)

Milner, A.D. \& Goodale, M.A. (1995) The visual brain in action. Oxford: Oxford University Press.

Oberauer, K., Schulze, R., Wilhelm, O. and Su“ $\beta$, H. (2005). Working Memory and Intelligence-Their Correlation and Their Relation: Comment on Ackerman, Beier, and Boyle. Psychological Bulletin, 131, 61-65.

O’Regan, K. (2003). Emotion and E-Learning. Journal of Asynchronous Learning Networks, 7, 78-92

Sankaran, S. R. and Bui, T. (2001). Impact of Learning Strategies and Motivation on Performance: A Study in Web-Based Instruction. Journal of Instructional Psychology, September, 1-9.

Skog, D., Hedestig, U. \& Kaptelinin, V. (2001). Supporting Social Interactions in Distance Education with a 3D Virtual Learning Space. In C. Montgomerie \& J. Viteli (Eds.), Proceedings of World Conference on Educational Multimedia, Hypermedia and Telecommunications 2001 (pp. 1751-1752). Chesapeake, VA: AACE.

van Harmelen, M. (2006). Personal Learning Environments. Proceedings of the Sixth International Conference on Advanced Learning Technologies (ICALT'06)

Warburton, S. \& Pérez-García, M. (2008). Motivating pupils, linking teachers through active learning with Multi-Users Virtual Environments. In Proceedings of World Conference on Educational Multimedia, Hypermedia and Telecommunications 2008 (pp. 3574-3578). Chesapeake, VA: AACE.

Widdowson, R. (posted 21st May, 2008). Designing effective learning environments. http://flux.futurelab.org.uk. Consulted August 08. (copy available from the present authors).

Williams, F.P. and Conlan, O. (2007). Visualizing Narrative Structures and Learning Style Information in Personalized e-Learning Systems. Seventh IEEE International Conference on Advanced Learning Technologies (ICALT 2007) 




\section{Advances in Human Computer Interaction \\ Edited by Shane Pinder}

ISBN 978-953-7619-15-2

Hard cover, 600 pages

Publisher InTech

Published online 01, October, 2008

Published in print edition October, 2008

In these 34 chapters, we survey the broad disciplines that loosely inhabit the study and practice of humancomputer interaction. Our authors are passionate advocates of innovative applications, novel approaches, and modern advances in this exciting and developing field. It is our wish that the reader consider not only what our authors have written and the experimentation they have described, but also the examples they have set.

\section{How to reference}

In order to correctly reference this scholarly work, feel free to copy and paste the following:

Ray Adams and Andrina Granic (2008). Technology Enabled Learning Worlds, Advances in Human Computer Interaction, Shane Pinder (Ed.), ISBN: 978-953-7619-15-2, InTech, Available from:

http://www.intechopen.com/books/advances_in_human_computer_interaction/technology_enabled_learning_w orlds

\section{INTECH}

open science | open minds

\section{InTech Europe}

University Campus STeP Ri

Slavka Krautzeka 83/A

51000 Rijeka, Croatia

Phone: +385 (51) 770447

Fax: +385 (51) 686166

www.intechopen.com

\section{InTech China}

Unit 405, Office Block, Hotel Equatorial Shanghai

No.65, Yan An Road (West), Shanghai, 200040, China

中国上海市延安西路65号上海国际贵都大饭店办公楼 405 单元

Phone: +86-21-62489820

Fax: +86-21-62489821 
(C) 2008 The Author(s). Licensee IntechOpen. This chapter is distributed under the terms of the Creative Commons Attribution-NonCommercialShareAlike-3.0 License, which permits use, distribution and reproduction for non-commercial purposes, provided the original is properly cited and derivative works building on this content are distributed under the same license. 